\title{
A dimensão sociológica das organizações e empresas
}

Waldyr Viegas (")

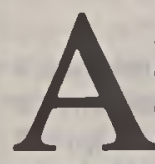

$s$ organizações são antes de tudo uma rede de relações sociais.

Por uma dessas miopias tão freqüentes na administração, a visão corrente sobre as organizações ou sobre as empresas sofre sérias deformações que obnubilam a mente dos administradores e obscurecem o processo decisório. Uma delas é a monopolização do subsistema técnico.

Tal deformação se manifesta tanto na relutância em se estender a qualificação de empresa nara além das organizações dedicadas à produçảo de bens ou serviços e com fins lucrativos, quanto na propensão dos administradores públicos ou privados de maximizar as funções voltadas diretamente para o objeto formalistico de suas organizações $\mathrm{cm}$ detrimento dos aspectos sociológicose administrativos.

Uma análise mais acurada vai mostrar, porém, que, na sua essência última, primária e imediata, a plena realização da empresa se dá através da função organização quando são realizados os processos de (1) divisão do trabalho, (2) de estabelecimento de estruturas de autoridade c de responsabilidade e (3) do desenvolvimento de processos de coordenação. O resultado desses processos é a criação de uma rede de relaçoes entre pessoas.

Vê-se, pois, que está configurada no fato administrativo pleno a interaçăo social e, por via de conseqüência, o fato social, uma vez que nele ocorrem açōes e reações entre mem-

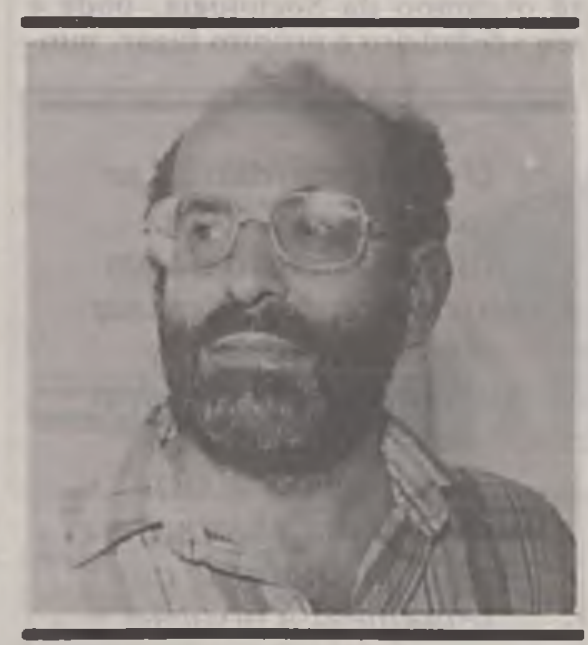

bros de um grupo com reciprocidade c coercitividade. Dai porque com freqüência, na linguagem corrente. a empresa é identificada como organização.

Uma rede de relaçð̃es internas

O que distingue o fato empresarial de outros fatos sociais e cle se constituir num sistema onde podem ser identificados três outros subsistemas: o subsistema tecnológico, o subsistema administrativo e o subsistema social.

O) subsistema tecnológico se caracteriza pelos elementos voltados diretamente para a realização física do objetivo estatutário da organizaçao, ou seja, para a produção de bens ou serviços. Por este subsistema cada empresa se distingue das outras, isto é, uma empresa é vista principalmente pela natureza do bem ou do serviço que ela produz e pela forma predominante de producảo ou de distribuição que adola.

- Doutor em Administraçáo pela Universidade de Grenoble (França), professor do Departamento de Administraçáo da Universidade de Brasilia (UnB) e auditor liscal do Tesouro Nacional.

O) subsistema administrativo se caracteriza pela forma peculiar de se reunir recursos materiais e humanos no sentido da realização do objetivo social da empresa. Discule-se quanto à natureza univoca ou analógica do fato administrativo, quer dizer. se o subsistema administrativo em sua essência seria distinto para cada calcgoria de empresa ou organizaçà; sc, por exemplo, a administraçao pública seria essencialmente distinta da administ ração privada.

() subsistema social se configura pelas interaçōes entre os membros da organizaça e desta com seu ambiente. Independentemente da organização, do produto realizado, da lecnologia empregada, do mercado ou da clientcla atingidos. do tino ou do modelo administrativo adotado. loda organização c um conjunto de interacies sociais, tanto formais quanto informais.

A posição relativa desses três sistemas no conjunto denominado organizaça ou empresa esta longe de ser linear. Pelo contrario, existe uma hierarquia entre cles. Li a analise mais minuciosa leva necessariamente a privilegiar o subsistema social cm relação aos demais. Tal supremacia do subsistema social sobre os demais se torna evidente seja pela redução dos outros dois subsistemas a cle, seja pelo carater essencial de interpenetrabilidade da organização com o ambientc.

A redução dos subsistemas técnico e administrativo ao subsistema social

Comecemos na análise nelo subsistema tecnico, por ser o que mais explicitamente parece ocupar o centro das preocupaçóes do administrador. Tais inquietaçòes se materiali- 
zam em angustiantes questões do tipo " o que vou produzir?", "como vou produzir?", "como vou atingir meu mercado?", "como vou vencer meu concorrente?" etc. Aqui seguramente se concentram os $80 \%$ das dores de cabeca, das úlceras, do stress ou de surmenage de executivos e administradores.

Ocorre, porém, que só uma visão estreita e limitada da realidade organizacional vai transformar o subsistema técnico num fim em si mesmo. De fato, de há muito, a tecnologia deixou de ser reduzida à simples técnica, quer dizer, à pura capacidade individual para a produção de bens ou serviços. Na realidade bens e serviços são produzidos por pessoas, fazendo parte de um grupo social, para serem consumidos ou utilizados por um mercado, também inserido num dado contexto social. $\dot{\mathrm{E}}$ por isso que hoje, na sociedade moderna e industrial, a tecnologia é entendida com um "conjunto de práticas sociais que transformam conhecimentos cientificos em saber utilizado na produção de bens ou servicos" (MADEUF, Bernadette. L'ordre technologique international: production et transfert. Paris, La Documentation Française, 1981. p. 13).

Que a tecnologia seja uma prática social fica evidenciado quando se comparam modos de produçio é de prestação de serviços em grupos sociais diversos, inclusive dentro de um mesmo pais. Cada socicdade tende a conformar sua mancira de produzir a seus padroes earateristicos ou comportamentos c atitudes, enfim, à sua cultura.

Quanto a subsistema administrativo, sua redutibilidade ar) subsistema social i patente, como o confirmam tanto a análise de seus elemenlos constitutivos quanto a Historia da Administração.

Administrar é um alo que implica interaçoes entre individuos c grupos no sentido de se atingir um objetivo comum. Nestas interacỏes entram em funcionamento elcmentos tais como formas e estilos de liderança, estruturas de poder, funcionamento de grupos, modelos de comunicação e culturas organizacionais; enfim, a adminisıração nào se reduz a formas de relacionamentos entre individuos, à semelhança de um contrato individual de trabalho entre o empregado e o empregador. mas a uma forma de exercicio de liderança e de comportamento grupal.

A ciência da Administração chegou a este estado através de um longo processo evolutivo e aproximativo de compreensão do fato administrativo. No principio, uma visão mecanicista mal conseguia distinguir o homem da máquina que ele manobrava ou do posto de trabalho que ocupava. A constatação, nem sempre fácil e gratuita, da inadequacão desta maneira de ver a empresa fez o estudo da Administração passar sucessiva e evolucionariamente para a P'sicologia e, finalmente, para o campo da Sociologia, onde é seu verdadeiro e próprio lugar, mui-

\begin{tabular}{|c|}
\hline O fato empresarial se \\
distingue pela sua \\
insercio dentro de um \\
sistema onde podem ser \\
identificados três \\
subsistemas: o social, o \\
idministrativo e o \\
tecnológico. Existe \\
'ntrc eles uma hierarquia \\
isto não permite que \\
sejal lincar a-posição \\
rclativa dentro \\
do sistcma da empresa \\
ou organização.
\end{tabular}

(1) cmbora sem excluir da análise os clementos de engenharia industrial e de realização individual no trabalho adquiridos nas fases anteriores.

\section{Empresa e ambiente}

Se vista de seu interior, a empresa sc constitui na inter-relação dinâmica dos três subsistemas analisados; vista de dentro para fora ela se apresenta como um sistema aberto. Toda organização está em continuo inlercâmbio de energias com seu ambientc. Através deste intercâmbio, cla tanto recebc influência do seu meio, quanto exerce influência sobre elc. Neste processo de influências mútuas, a organização, de um lado, c o reflexo do seu ambiente, absorvendo sua cultura e seu modo de ser; de outro, é um poderoso fator de modificação do ambiente.

Sem falar das modificaçoes visivcis e superficiais induzidas pela organização no próprio mercado, no meio físico e geográfico ou nos hábitos de consumo, modificaçōes mais profundas e, por isso, menos observáveis ao olhar superficial ocorrem na adoção, pela sociedade dos valores da organização. Tais valores tanto podem estar imbutidos nos produtos da organização quanto podem ser induzidos pela modificação dos seus membros.

É exercendo influência sobre o ambiente que a empresa se transforma num instrumento inexorável de mudança social e numa portadora de valores para a sociedade. É como instrumento de mudança que a empresa atinge a excelência de suas dimensões.

\section{Relaçes externas}

A função de agente de mudança na sociedade é um dado inerente e inevitável da existência da empresa na sociedade. Mas essa influência está sujeita a algumas regras que determinam seu alcance e eficácia.

Há uma inexorabilidade da influência da empresa sobre o ambiente.

Embora a definição clássica de ambiente seja aquele espaço onde o sistema atua, mas sobre o qual não exerce poder, isto não quer dizer que o sistema não possa influenciálo. Pelo contrário. A influência do sistema aberto sobre o ambiente é unı própria dele. tendo em vista a troca de energia entre ambos. Desta forma, a empresa modifica seu ambiente, queira-o ou não, saiba-o ou desconheça-o. Esta influência ocorre sob duas formas: diretamente, sobre os individuos pertencentes à organização e, indiretamente, através do produto que ela oferece ao mercado.

Quando se fala na Teoria de Sistemas de transformação dos inputs, a primeira imagem que aflora à mente co processamento da matéria-prima $\mathrm{cm}$ produtos acabados. Esta, porém, é a Iransformação mais visivel todavia seguramente não é a mais importante nem a mais profunda. A Iransformação mais profunda é a da mão-de-obra. A empresa é um fator direto de mudanças do ambiente porque modifica os individuos que nela trabalham.

A cmpresa transforma a mão-deobra desde o inicio de sua contrata(ão. () contrato de trabalho só juridicamente pode ser considerado como uma relaça individual entre o cmpregado e seu empregador. Na 


\section{IDÉIAS}

realidade esse contrato cria um complexo sistema de relaçoes e de mútuas influências que atingem $0 \mathrm{em}$ pregado e sua familia, sua categoria profissional e seu sindicato, suas relaçóes com o Estado, com o sistema previdenciário e com a estrutrura fiscal, entre outras.

Além disso, a empresa transforma todo o corpo social constituido pelo seu pessoal porque nela ele desenvolve formas peculiares de comportamento, de agir e de reagir, enfim, desenvolve uma cultura propria e conforme a empresa. Realmente não se pode imaginar que um individuo, passando a maior parte de sua vida útil dentro de determinado lipo de organização não fique infenso às suas influências e possa se imunizar dela no dominio de suas relações fora da organização. Seja, pois, em função do tempo vivido na organização, seja pelo processo de socialização a que è submetido em razão do papel que exerce profissionalmente, os individuos se transformam cm membros da sociedade, transformados pela cultura da organização.

Entretanto, maior é ainda a influência exercida pela empresa sobre o ambiente, e sobre a qual ela é mais diretamente responsável, que deriva imediatamente do produto que ela lanca no mercado. Cumpre alertar, porém, que produto não é tãosomente o resultado direto do funcionamento do subsistema técnico, mas, e principalmente, é o conjunto de valores que a empresa alimenta, incorpora e difunde no ambiente.

A empresa é uma difusora de valores

A empresa é um organismo que cria c difunde valores sociais. E por meio deles que ela se insere, é aceita e conhecida na sociedade. E o chamado processo de instilucionalizacão, isto ć, o processo pelo qual a empresa deixa de ser um instrumento meramente técnico para se transformar numa instituição, vale dizer, num organismo capaz de infundir valores sociais alèm das exigências técnicas de suas tarefas quotidianas. Neste estágio, a empresa passa a simbolizar aspiraçōes da comunidade e seu senso de identidade.

No dizer de Selznick, como meros instrumentos técnicos, as organizações são planejadas para cumprir tarefas especificas. São meros projetos, perecíveis como seu próprio

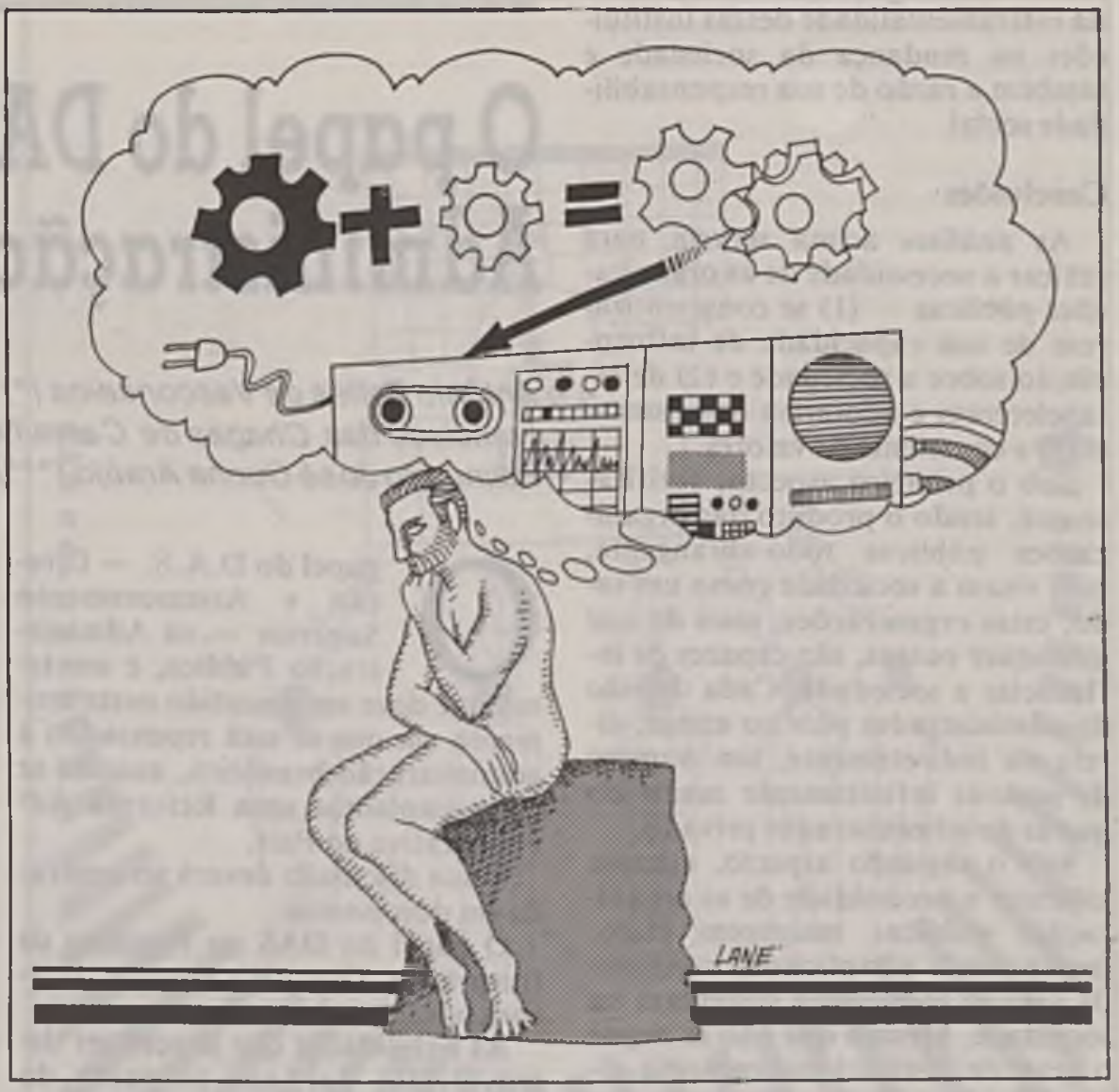

produto. Como instituiçōes, possuem uma dimensão própria e natural. Resultam de interaçōes com o meio, sendo receptáculo das aspiracões e dos valores do grupo social (Selznick, Philip. A liderança na administração: uma interpretaçào sociológica. Rio de Janeiro, Fundação Getúlio Vargas, 1971. p.9).

Condiçōes de influência

$O$ grau de eficácia da influência

\begin{tabular}{c}
\hline A constatação de que \\
existe uma grande \\
diferença entre o homem \\
e a máquina - superada a \\
visão mecanicista da \\
sociedade industrial - fez \\
o estudo de administracão \\
passar sucessivamente pela \\
psicologia e, finalmente, \\
para o campo da \\
sociologia, em todas as \\
suas manifestaçōes nos \\
paises, dos menos aos \\
mais desenvolvidos.
\end{tabular}

sobre a sociedade é função de duas variáveis: o grau de institucionalizacão e o grau de indiferenciação do produto social.

Tanto maior influência exerce sobre o ambiente quanto mais institucionalizada for a organização. A institucionalização, com efeito, é o elemeato que confere à empresa sua identidade, sua cor, sua personalidade especifica, independente de seu produto.

Por outro lado, o nivel de influência é inversamente proporcional ao grau de diferenciação do produto. Desta forma, empresas com produlos com menor grau de diferenciacão, como as instituiçōes de ensino ou os centros de pesquisa e outros desta categoria teriam maior capacidade de influenciar a sociedade do que aquelas organizaçóes volıadas alto grau de diferenciação.

Instituiçoes financeiras, por exemplo, têm também grande capacidade de modificaça do ambiente, visto lidarem com um produto que é um recurso todo-abrangente, intermediário e indiferenciado, o próprio denominador comum de todas as transaçōes. Neste fato reside a base para um bem material, fisico, com 
da instrumentalidade dessas instituições na mudança da sociedade e também a razão de sua responsabilidade social.

\section{Conclusões}

As análises acima servem para realçar a necessidade de as organizações públicas (1) se conscientizarem de sua capacidade de influenciação sobre a sociedade e (2) de estabelecerem e adotarem um sistema claro e consciente de valores.

Sob o primeiro aspecto, verificase que, sendo o produto das organizações públicas todo-abrangente, pois visam a sociedade como um todo, estas organizaçōes, mais do que quaisquer outras, são capazes de influenciar a sociedade. Cada decisão do administrador público atinge, direta ou indiretamente, um número de pessoas infinitamente maior do que as do administrador privado.

Sob o segundo aspecto, cumpre salientar a necessidade de as organizações públicas manterem claro, transparente e explícito o conjunto de valores sociais que sustentam na sociedade. Mesmo que não se negue o grau de institucionalizaça já alcançado por muitas organizações públicas brasileiras, é proveitoso insistir sobre o fato de que a institucionalização é um processo e, como tal, está sempre in ficri. essencialmente inacabado e incompleto, capaz de avanços e progressos, mas também sujeito a recuos c esmaecimentos.

Dizem os psicólogos que existem três medos naturais no homem: o medo de perda de equilibrio, o medo do barulho e o medo do desconhecido. O medo da escuridà é um medo derivado da consciência de que a escurid æo traz o desconhecido. A atividade tipica do adminisIrador é a tomada de decisão. Apesar de lodos os recursos informacionais disponiveis atualmente, a decisão é sempre um salto no escuro. $O$ administrador consciente e clarividente decide com medo, mesmo quando sua decisão é firme e segura, pois sabe aquilatar a importância de seu ato. $\mathrm{O}$ administrador inconsciente não tem medo de decidir porque desconhece seu próprio ato de decidir. E o medo, dizem ainda os psicólogos, aumenta o voluntário: quem age com medo (não por medo) tem mais vontade de agir e usa de maior energia na ação.
IDÉIAS

\section{$O$ papel do DASS na Administração Pública}

\author{
Antônio Telles de Vasconcelos (") \\ Francisco das Chagas de Carvalho Neves (") \\ Raimundo José Cunha Araújo (*" ")
}

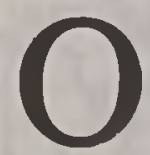

papel do D.A.S. - Direçao e Assessoramento Superior - na Administração Pública, é um tema que deve ser discutido neste momento em que se está repensando a administração brasileira, quando se tenta implantar uma Reforma Administrativa no Pais.

A sua discussão deverá ser centrada eill dois pontos:

O papel do DAS no Processo de Integração Organizacional e Interorganizacional e

As habilidades que devem ser desenvolvidas por um ocupante do Grupo DAS.

Ėssas sảo as questðes básicas.

Envolvem, de modo geral, toda a problemática da função de assessoramento e direção superior na administração pública, onde o gerente icm de enfrentar problemas de toda ordem, para cumprir a sua missão num emaranhado da burocracia que prende à terra (à organização), lhe prende os braços nos movimentos inútcis da disfunçào burocrática e lhe embotam o cérebro pelas rotinas cxistentes e pelas que tem de seguir e fazer seguir, rigorosamente conforme o figurino. Mas, antes de tudo, o DAS é um gerente da coisa pública,e este é um momento que exige reflexão para uma mudança radical na postura administrativa, se quisermos interagir com o ambiente; se quisermos fazer com que a organização onde trabalhamos acompanhe o ritmo do ambiente que a cerca e que está a exigir cada vez mais uma definição, um novo caminho a percorrer.

- Administrador e coordenador de Desenvolvimento Gerencial da Funcep (Fundaçao Centro de Formaçáo do Servidor Público)

- Administrador e professor de Planejamento Governamental na Fufpi (Fundacáo Universidade Federal do Piaul)

*.. Administrador e prolessor de Administraçăo Geral na Fufpi (Fundaçáo Universidade Federal do Plaul) 